* Graduado em Direito pela Univ. Católica de Pernambuco, Especialista em Direito pela Universidade de Salamanca, Mestre em Direito pela Universidade de Lisboa e Doutorando em Ciência Política pela Universidade Federal de Pernambuco (UFPE). Professor do Curso de Direito da UFERSA. E-mail: roalmleite@gmail.com

** Doutorando na UNB. Mestre em Direito pela Universidade Federal da Paraíba (UFPB). Professor de Direito Ambiental na Universidade Estadual do Rio Grande do Norte (UERN) e na Universidade Federal Rural do Semi-Árido (UFERSA). E-mail: marcus tullius@ufersa.edu.br

\section{Incongruências na criação de unidades de conservação: um Estudo de Caso da "Flona de Açu"}

\section{INCONGRUITIES ON THE CREATION OF PROTECTED areas: a Case Study Of The "Flona De AÇu"}

\author{
* Rodrigo de Almeida Leite \\ ** Marcus Tullius Leite Fernandes dos Santos
}

Resumo: Este artigo utiliza o método do estudo de caso para analisar a criação da Floresta Nacional de Açu, mais conhecida como Flona de Açu, localizada no município de Assú, Estado no Rio Grande do Norte. Observou-se que existem ilegalidades formais na criação da Flona de Açu que estão gerando conflitos de gestão de informação com os diversos órgãos ambientais (nível municipal, estadual e federal). Um exemplo disto foi a permissão da criação de uma Zona de Processamento de Exportação (ZPE) na mesma área da Floresta. Desta forma, procura-se alertar que no caso da Flona de Açu, sua criação deveria ter ocorrido por um processo mais democrático, de forma a permitir uma melhor integração entre os diversos órgãos ambientais.

Palavras-Chave: Unidades de Conservação. Floresta Nacional. Ilegalidade.

Abstract: This article uses the case study method to analyze the creation of the National Forest Acu, better known as "Flona Acu", located in the city of Assú, State of Rio Grande do Norte. It was observed that there are formal illegalities in the creation of Flona Acu that are generating conflicts of information management with the various environmental agencies (municipal, state and federal). An example of this was the permission of creation of a Export Processing Zone (EPZ) in the same area of the Forest. Thus, it seeks to warn that if Flona Acu, its creation should have occurred by a more democratic process, to allow better integration between the various environmental organs.

Keywords: Conservation Units. National Forest. Illegality. 


\section{INTRODUÇÃO}

O presente artigo visa estabelecer um alerta sobre a criação de Unidades de Conservação e a integração destes espaços protegidos com os diversos órgãos ambientais.

Através de um estudo de caso da Flona de Açu, criada no município de Assú, Rio Grande do Norte, busca-se mostrar que a mesma foi criada por meio de uma Portaria do ICMBIO e não por meio de lei, como deveria ser. Note-se que não se está com este ensaio querendo apontar que a floresta não devesse ser criada. O que se deseja chamar a atenção é que a sua criação possui efeitos em outros direitos, como o direito de propriedade, e que se as informações entre os órgãos ambientais e locais não forem bem gerenciadas, poderão ocorrer diversos litígios judiciais.

No presente caso, inclusive uma Zona de Processamento de Exportação (ZPE) foi criada na mesma área da Flona de Açu. Isto demonstra que há um total descompasso entre os órgãos ambientais do SISNAMA, devido ao vício de formalidade na criação da floresta.

De fato, o processo de criação da Flona de Açu deveria ter sido mais democrático, através de lei aprovada pelo Congresso Nacional, e não uma simples portaria de um órgão público.

O planejamento ambiental local e a integração entre os órgãos ambientais, no âmbito da Flona de Açu, tem sido bastante prejudicado com a ausência de informações e com esta ilegalidade apontada. É com este sentido que alertamos a comunidade para a discussão e correção das irregularidades na criação da Flona de Açu.

\section{DA PROTEÇÃO AMBIENTAL MEDIANTE A CRIAÇÃO DAS UNIDADES DE CONSERVAÇÃO}

Para a proteção da fauna e da flora (bens ambientais), o sistema de proteção ambiental no Brasil, através da Política Nacional do Meio Ambiente PNMA (Lei n. ${ }^{\circ} 6.938 / 81$ ), concebe que os entes públicos, nos diversos níveis de governo, instituam os "espaços territoriais especialmente protegidos". O grau de sua importância está em que a PNMA concebe esses "espaços" como um dos instrumentos para a garantia da compatibilização entre o desenvolvimento econômico-social e a preservação da qualidade do meio ambiente e seu equilíbrio ecológico, a teor do disposto no art. 9. ${ }^{\circ}$, inciso VI: 
Art. $9^{\circ}$ - São instrumentos da Política Nacional do Meio Ambiente:

$[\ldots]$

VI - a criação de espaços territoriais especialmente protegidos pelo Poder Público federal, estadual e municipal, tais como áreas de proteção ambiental, de relevante interesse ecológico e reservas extrativistas.

Reconhecendo a importância da instituição dos "espaços territoriais especialmente protegidos", a Constituição Federal de 1988 recepcionou a PNMA, ressaltando que este instrumento deve ser "efetivo" e que o "Poder Público" deve aplicá-lo no mundo dos fatos, de forma que se trata de norma de aplicação imediata, consoante definido na Carta Magna atual:

Art. 225. Todos têm direito ao meio ambiente ecologicamente equilibrado, bem de uso comum do povo e essencial à sadia qualidade de vida, impondo se ao Poder Público e à coletividade o dever de defendê lo e preservá lo para as presentes e futuras gerações.

$\S 1^{\circ}$ Para assegurar a efetividade desse direito, incumbe ao Poder Público:

III definir, em todas as unidades da Federação, espaços territoriais e seus componentes a serem especialmente protegidos, sendo a alteração e a supressão permitidas somente através de lei, vedada qualquer utilização que comprometa a integridade dos atributos que justifiquem sua proteção;

Seguindo os aspectos da federação brasileira, o Poder Constituinte ressaltou a importância de todos os níveis de governo na criação desses "espaços", atento as peculiaridades nacionais, regionais e locais, de forma que acaba descentralizando a instituição das Unidades de Conservação - UC, conforme a predominância do interesse. Com isso, no sistema de gestão ambiental no Brasil é perfeitamente possível a existência de "Espaços Territoriais Especialmente Protegidos" em todas as unidades da Federação, embora a grande maioria dos Municípios brasileiros não venha aplicando esse instrumento na gestão ambiental urbana e rural.

Um breve parêntese pode ser anotado sobre essa questão dos municípios. Consiste no fato de que os mesmos utilizam o argumento da restrição ao uso da propriedade urbana, de forma a limitar a expansão da atividade comercial e industrial. Por outro lado, aguarda-se que o Congresso Nacional aprove o projeto 
de Lei que trata dos incentivos financeiros ambientais, de forma que aqueles Municípios que passarem a instituir Unidades de Conservação em seus territórios seriam agraciados com maior repasse do Fundo de Participação Municipal FPM pelos Estados e pelo Governo Federal ${ }^{1}$.

No Brasil, estes espaços territoriais especiais são divididos em duas grandes categorias: a) lato sensu: Área de Reserva Legal - ARL (definida no Código Florestal); Área de Preservação Permanente - APP (definida no Código Florestal); Biomas considerados patrimônio nacional (previstos na Constituição Federal, art. 225, § 4..$^{\circ}$ ); Reserva Exclusiva (prevista na Lei de Gestão das Florestas Públicas); Servidão Ambiental (prevista no Código Florestal); b) stricto sensu: Unidade de Conservação - UC (prevista na Lei n. ${ }^{\circ}$ 9.985/2000, que institui o Sistema Nacional de Unidades de Conservação da Natureza).

Sobre o tema, Santos (2009, p. 137) explica que a criação de áreas protegidas é um dos "instrumentos mais utilizados em todo o mundo, no sentido de buscar formas alternativas de frear a degradação ambiental. No Brasil, essas áreas tomaram a nomenclatura de unidades de conservação".

Neste sentido, o presente trabalho refere-se a discussão sobre Unidade de Conservação - UC, especificamente a Floresta Nacional de Açu - "FLONA DE AÇU", que está entre uma das categorias de UC, enquadrada como Floresta Nacional de uso sustentável, ou seja, que permite a exploração de atividade econômica na área. Esta Unidade de Conservação foi criada através da Portaria n. 245, de 18 de julho de 2001, do Instituto Chico Mendes de Conservação da Biodiversidade, tendo o seu Conselho Consultivo constituído em 29 de agosto de 2008, através da Portaria n. 57, de 28 de agosto de 2008, do mesmo órgão.

O ICMBIO defende que na prática, houve uma recategorização da referida unidade de conservação pela Portaria MMA n. ${ }^{\circ} 245$, de 18 de julho de 2001, transformando o anterior Horto Florestal de Açu, criado pela Lei n. ${ }^{\circ} 1.175$, de 10 de agosto de 1950, na Floresta Nacional de Açu. Ou seja, a Flona de Açu realmente foi definida por Portaria e não por LEI.

A Flona de Açu está localizada no município de Assú, região semi-árida do Rio Grande do Norte, tendo o seu relevo caracterizado como suave e

\footnotetext{
1 O texto (PLP 83/11) altera o Código Tributário Nacional (Lei 5.172/66) e a lei complementar (LC 91/97) que fixa os coeficientes do Fundo de Participação dos Municípios. De acordo com o projeto, $2 \%$ do FPM serão repartidos entre os municípios onde estejam instalados territórios indígenas, parques nacionais, reservas biológicas, estações ecológicas, florestas nacionais e reservas extrativistas federais. O projeto foi apensado a outras propostas de lei complementar, e ainda encontra-se em discussão. Disponível em: http://www.camara.gov.br/proposicoesWeb/fichadetramitacao? idProposicao $=514942$, acesso em 06/02/2015.
}

Revista do Direito Público, Londrina, v.10, n.3, p.141-154, set./dez.2015 | DOI: 10.5433/1980-511X.2015v10n3p141 
ondulado, e sua formação vegetal com predominância de caatinga, "com um aspecto fisionômico marcado por uma formação vegetal do tipo arbóreaarbustiva densa" (LIRA et al., 2007, p. 2). O principal objetivo que deve ser mantido mediante a proteção do manto legal, é promover o manejo adequado dos recursos naturais, garantir a proteção dos recursos hídricos e das belezas cênicas, fomentar o desenvolvimento da pesquisa científica básica e aplicada, da educação ambiental e das atividades de recreação, lazer e turismo.

Sob o aspecto crítico, há uma questão interessante a ser discutida na instituição da Flona de Açu, pois a mesma não foi instituída por lei, dispensando, inclusive, o estudo técnico e a consulta pública à população. Na realidade, foi feita tão-somente uma conversão do Horto Florestal de Açu em Floresta Nacional de Açu, por mera deliberação administrativa, isolada e antidemocrática, do Ministério do Meio Ambiente - MMA, relegando ao oblívio a função legislativa do Congresso Nacional.

Discutiu-se anteriormente que a Unidade de Conservação somente pode ser instituída por lei. É o que se extrai da interpretação do art. $2^{\circ}{ }^{\circ}$, inciso I, da Lei n. ${ }^{\circ}$ 9.985/2000:

Art. $2^{\circ}$. Para os fins previstos nesta Lei, entende se por:

I unidade de conservação: espaço territorial e seus recursos ambientais, incluindo as águas jurisdicionais, com características naturais relevantes, legalmente instituído pelo Poder Público, com objetivos de conservação e limites definidos, sob regime especial de administração, ao qual se aplicam garantias adequadas de proteção.

Percebe-se que a Unidade de Conservação deve ser "legalmente instituída". Isto porque deve haver uma discussão para sua criação, notadamente dos aspectos técnicos, devendo se dar mediante discussão e votação no Congresso Nacional, transformando-se em lei. Seria um absurdo imaginar que um órgão, que não o Congresso Nacional, possa instituir Unidade de Conservação, já que isso importa em restrição ao direito de propriedade previsto na Constituição Federal. Some-se a isso que ninguém está obrigado a fazer ou deixar de fazer alguma coisa senão em virtude de lei.

O Supremo Tribunal Federal, em sua composição plena, julgando caso em que se discutia a ampliação dos limites originais de Unidade de Conservação da categoria Estação Ecológica, entendeu ser inadmissível a utilização de Decreto do Presidente da República. Note-se então que uma simples Portaria 
do Ministério do Meio Ambiente não poderia ter o condão de criação de unidades de conservação. Vejamos a Ementa do referido caso:

MEIO AMBIENTE. UNIDADE DE CONSERVAÇÃO. ESTAÇÃO ECOLÓGICA. AMPLIAÇÃO DOS LIMITES ORIGINAIS NAMEDIDADO ACRÉSCIMO, MEDIANTE DECRETODO PRESIDENTE DA REPÚBLICA. INADMISSIBILIDADE. Falta de estudos técnicos e de consulta pública. Requisitos prévios não satisfeitos. Nulidade do ato pronunciada. Ofensa a direito líquido e certo. Concessão do mandado de segurança. Inteligência do art. 66, $\S \S 2 .^{\circ}$ e $6^{\circ}$, da Lei n. ${ }^{\circ} 9.985 / 2000$. Votos vencidos. A ampliação dos limites de estação ecológica, sem alteração dos limites originais, exceto pelo acréscimo proposto, não pode ser feita sem observância dos requisitos prévios de estudos técnicos e consulta pública. (STF; MS 24.665-1; Tribunal Pleno; Rel. Min. Cezar Peluso; Julg. 01/12/2004: DJU 06/10/2006: pág. 33).

Portanto, a criação da Flona de Açu, mediante Portaria do Ministério do Meio Ambiente, afronta o princípio da legalidade, do Estado de Direito e até a segurança jurídica em sociedade, pois do contrário, permitir-se-á que os órgãos da Administração Pública passem a legislar, impondo suas próprias restrições aos administrados, sem que tenham o crivo do Congresso Nacional. Vejamos como o Superior Tribunal de Justiça, julgando caso análogo, interpretou a questão:

PROCESSUALCIVIL. AGRAVO REGIMENTALNO RECURSO ESPECIAL. IMPOSIÇÃO DE SANÇÃO COM ARRIMO EM PORTARIA. IMPOSSIBILIDADE. PRECEDENTES DE AMBAS AS TURMAS QUE COMPÕEM A SEÇÃO DE DIREITO PÚBLICO DO STJ. 1. A jurisprudência assente no âmbito das Turmas que compõem a Seção de Direito Público do STJ é no sentido de que: "Só a Lei em sentido formal ou material é meio hábil para impor sanção" (RESP 274.423/SP, Relator Ministro João Otávio de Noronha, Segunda Turma, DJ de 20 de março de 2006). Outro Precedente: AGRG no AG 901.949/SP, Relator Ministro José Delgado, Primeira Turma, DJ 10 de dezembro de 2007. 2. No caso sub examinem, a agravante assevera a impossibilidade do julgamento monocrático em razão de supostamente existirem julgados desta Corte em sentido contrário àquele alvitrado pelo decisum agravado. Sucede que os precedentes colacionados por ela no bojo do seu arrazoado recursal conferirem poder normativo de regulação ao $\mathrm{Sr}$. Ministro de Estado de Minas e Energia, que se manifesta com a edição de portarias, a fim de disciplinar a atividade exercida pelas pessoas ou pelos entes sobre os quais a agência reguladora atua. Logo, ressoa inequívoco que esse entendimento não atribui à ora agravante poder de aplicar multa 
pecuniária que não esteja prevista em Lei, porquanto o princípio da legalidade estrita deve permear os atos da Administração Indireta. 3. Agravo regimental não provido. (Superior Tribunal de Justiça, AgRg REsp 1.134.417, Proc. 2009/ 0156939 9, MG, Primeira Turma, Rel. Min. Benedito Gonçalves; Julg. 24/11/ 2009; DJE 01/12/2009).

Em que pese a importância da questão ambiental, ela deve ser tratada corretamente. Se tecnicamente o Ministério do Meio Ambiente aferiu a importância ecológica da suposta "Floresta Nacional de Açu", que encaminhe o projeto de Lei para o Congresso Nacional para que a mesma seja protegida por lei. Ao mesmo tempo, talvez um caminho mais curto fosse o Ministério do Meio Ambiente propor ao Município de Açu que institua a Flona de Açu como unidade de conservação local. Mas tudo isso, respeitando-se o princípio da legalidade, sem utilização de Portarias e tampouco usurpando a função do Legislativo.

\section{A CRIAÇÃO DA ZONA DE PROCESSAMENTO DE EXPORTAÇ̃̃̃O DO SERTÃO DENTRO DA ÁREA DA FLONA AÇU COMO GARANTIA DO PLANEJAMENTO URBANO E O CONFLITO NA GESTÃO DA INFORMAÇÃO ENTRE OS ÓRGÃOS GOVERNAMENTAIS}

O Município de Assú, dentro da sua competência instituída pelo art. 182, da Constituição Federal de 1988, editou a Lei n. ${ }^{\circ}$ 303, de 28 de dezembro de 2009 (que dispõe sobre a Zona de expansão urbana do Município de Assú/RN e dá outras providências). Conforme estatuído no seu art. 3. ${ }^{\circ}$, "a Zona de Expansão Urbana é uma área contígua à Zona Urbana criada pela Lei n. ${ }^{\circ}$ 19/ 89 e constitui reserva para a sua expansão, com vista a receber novas edificações e serviços públicos, em uma projeção de 20 (vinte) anos".

No mesmo ano, o Município de Assú, através do Decreto n. ${ }^{\circ} 013$, de 21 de julho de 2009, declarou como de utilidade pública para fins de desapropriação a área que coincide com a Flona de Açu. O principal objetivo do Município é de instalar a "Zona de Processamento de Exportação - ZPE", com a finalidade de criar novas perspectivas de desenvolvimento para o município de Açu. Referido ato foi chancelado pelo Presidente da República, que através do Decreto de 10 de junho de 2010, criou a "Zona de Processamento de Exportação do Sertão, no Município de Assú, no Estado do Rio Grande do Norte, numa área total de $1.019,98$ hectares". 
Esta ZPE do Sertão está instalada em uma região que já conta com estrutura básica, água tratada e encanada, cabeamento ótico, energia, sinal de telefonia celular e internet, tendo como principal atrativo a pauta de exportação e potencialidades econômicas do Rio Grande do Norte, que apontou que a área terá um potencial para desenvolvimento de indústrias de alimentos principalmente para beneficiamento de frutas e frutos do mar -, produtos químicos, sal e recursos minerais. Além destes fatores, o estudo de viabilidade econômica realizado para a criação desta ZPE, esclareceu que os seguintes países são mercados potenciais para as empresas que ali se instalarem: Estados Unidos, Holanda, Espanha, França, Reino Unido, Argentina, Líbia, Itália, Canadá e Nigéria.

Conforme noticiado na imprensa potiguar, o "projeto da ZPE do Sertão promete gerar o desenvolvimento sonhado no Vale do Açu", de forma que o município "depende de emenda parlamentar" para consolidação da ZPE, já que o "prefeito espera conseguir R $\$ 17$ milhões com a bancada federal do $\mathrm{RN}$, para iniciar a estrutura física"2.

\footnotetext{
${ }^{2}$ Veja-se reportagem sobre esta ZPE do Sertão: "O prefeito Ivan Lopes Júnior deposita suas fichas na aprovação de uma emenda ao Orçamento Geral da União (OGU), para alocação de recursos da ordem de R \$ 17 milhões para estruturar o município de Assú, que anseia pela implantação da Zona de Processamento de Exportação (ZPE do Sertão). Segundo o prefeito, a discussão com a bancada está nas mãos da senadora Rosalba Ciarlini, do senador José Agripino e do deputado federal Fábio Faria. Ele explica que os recursos são fundamentais para que o município de Assú seja adequado à área alfandegária que deve ser instalada. Pavimentação, estradas e outras estruturas físicas são essenciais para receber as grandes empresas, nacionais e internacionais, que podem implantar unidades em seu território. No próximo sábado, 26, a Prefeitura de Assú assinará contrato com a empresa que ficará responsável pela administração da ZPE. A partir de sábado, a municipalidade terá um prazo de 90 dias para enviar o projeto de alfandegamento. As obras devem ser iniciadas até julho, do contrário, corre o risco de perder autorização do Ministério do Desenvolvimento, Indústria e Comércio Exterior (MDIC), para ser instalada. Em duas tentativas de promover licitação pública com este propósito não surgiram concorrentes interessados em participar do certame. Por conta disto, de acordo com os critérios legais, o município se habilitou legalmente a efetuar a contratação diretamente, procedimento que já está sendo trabalhado administrativamente na instância da consultoria jurídica e Comissão Permanente de Licitação (CPL). A destinação da emenda coletiva indicada pelos membros da bancada potiguar ao Orçamento Geral da União (OGU), corresponde ao exercício 2011, poderá contemplar aquele que desde já é considerado o projeto capaz de revolucionar social e economicamente o Vale do Açu e o interior do Rio Grande do Norte - a Zona de Processamento de Exportação (ZPE) do Sertão. Ivan Júnior declarou que já pode preliminarmente tratar do tema com o coordenador da bancada, deputado federal Fábio Faria, e pretende abrir diálogo com o mesmo propósito com os demais integrantes da banda. De acordo com ele, somente no estágio inicial, a implantação da ZPE do Sertão será objeto de investimentos da ordem de R\$ 21 milhões. Ivan pretende fazer gestões para assegurar um considerável aporte orçamentário com este fim $\mathrm{O}$ otimismo é a coisa mais certa que o prefeito possui. O chefe do Executivo reiterou a disposição de conversar com cada parlamentar com o objetivo de viabilizar a emenda coletiva que faça frente aos interesses do mega projeto. 'Permanecemos com o entendimento de que a ZPE do Sertão, em se tornando uma realidade, será um verdadeiro divisor de águas para o incremento social e econômico do Estado', observou o prefeito". Jornal de Fato, coluna "Estado", p. 3, edição de 24/11/2010. Disponível em: <www.defato.com>. Acesso em: 02 fev. 2013.
}

Revista do Direito Público, Londrina, v.10, n.3, p.141-154, set./dez.2015 | DOI: 10.5433/1980-511X.2015v10n3p141 
Referido projeto não envolve somente o município de Assú, mas o Governo do Estado do RN, Governo Federal e diversos municípios da região do $\mathrm{RN}$, todos com o objetivo de firmar laços mais sólidos para consolidação da ZPE. A ótica é transformar o Sertão em um potencializador de transformação desenvolvimentista do Rio Grande do Norte. Tal fato poderia se dar com a celebração de um mega consórcio intermunicipal.

A Zona de Processamento de Exportação possui como característica ser uma área de livre comércio, voltada à instalação de empresas que visam a produção de bens a serem comercializados, em parte, no exterior, e que passam a ter um regime aduaneiro e cambial especial. Este tratamento diferenciado permite uma maior competitividade nos mercados internacionais - inclusive com produtos oriundos de outras ZPE's - considerando-se estas regiões como um mecanismo compatível e complementar à estratégia de competitividade das empresas industriais em novos mercados.

Por sua vez, os temas relacionados às ZPE's são dirimidos pelo Conselho Nacional das Zonas de Processamento de Exportação (CZPE), colegiado este vinculado ao Ministério do Desenvolvimento, Indústria e Comércio Exterior (MDIC).

Vale salientar que as Zonas de Processamento de Exportação (ZPE's) são áreas criadas com a finalidade de reduzir desequilíbrios regionais, além de estimular o desenvolvimento econômico e social do país em regiões menos desenvolvidas. Nesse sentido, a lei n. 11.508/2007, que disciplina o regime administrativo e tributário dessas regiões, em seus artigos $1^{\circ}$. e $2^{\circ}$., estipula que a criação das ZPE's far-se-á por meio de decreto presidencial, tendo como um dos requisitos a "comprovação da área a ser disponibilizada".

Ora, a própria lei que rege o tratamento das ZPE's determina que para sua criação, deve ser verificada a sua disponibilidade. Nesse sentido, o Conselho Nacional das Zonas de Processamento de Exportação não levou em consideração a existência da Flona de Açu - quiçá por sua ilegalidade perante o ordenamento jurídico, já que foi instituída por Portaria e não por Lei.

Este vício de legalidade da Flona de Açu pode ter origem no próprio desentendimento entre os órgãos ambientais e a falta de democratização do processo inicial de criação das Unidades de Conservação (UC's). Como se sabe, com a entrada em vigor da Lei n. 9.985/2000, foi designado que as UC's possuam um conselho consultivo, visando uma gestão participativa no uso e na distribuição dos bens naturais. 
No entanto, de acordo com Loureiro e Cunha (2008, p. 246), o fato de que muitas UC's terem sido criadas de cima para baixo - ou seja, através da edição de um ato unilateral dos órgãos ambientais, sem uma maior discussão no seio da sociedade e perante os seus representantes no Poder Legislativo - tem dificultado a tomada de decisões e a confiança no seio dos conselhos que gerenciam as UC's, posto que uma gestão participativa, quando se trata do Sistema Nacional de Unidades de Conservação, deveria ser concebida como iniciada anteriormente ao ato de criação da Unidade, "através de consultas públicas, com ampla participação dos setores envolvidos na definição da localização, dimensão e limites da UC, como preconiza a lei, e de debates sobre a categoria a ser adotada". Ainda para os referidos autores, a criação dos conselhos tem se tornado, em grande parte, o primeiro momento de discussão dos conflitos envolvendo a Unidade, o que poderia ser evitado com a participação prévia da sociedade e a discussão nas casas legislativas do País, como determina a legislação aplicada à espécie (LOUREIRO; CUNHA, 2008, p. 246).

É possível, com essas informações, vislumbrar um cenário conflituoso num futuro bem próximo, envolvendo discussões sobre o direito de propriedade e a função social nas áreas de interseção entre a "Flona de Açu", a "ZPE do Sertão" e as "áreas de expansão urbana". Ao mesmo tempo, isso requer uma atenção especial dos governos federal, estadual e municipal, para a compatibilização do desenvolvimento econômico-social com a preservação ambiental.

Certamente, na fase em que os projetos econômicos, ambientais e urbanos se encontram já há, pelo menos, um conflito entre o planejamento urbano do município de Assú com a Unidade de Conservação. É preciso que o órgão municipal de planejamento urbano e o órgão estadual responsável pelo licenciamento ambiental estejam plenamente cientes dessa realidade conflituosa, e possam exercer o controle preventivo pelos instrumentos de outorga, seja mediante a expedição de alvará de construção ou das licenças ambientais. Sem isso, teremos sérios problemas de competência administrativa a afligir o modelo federativo brasileiro.

Sobre a temática da atuação descompassada entre o órgão estadual de meio ambiente licenciador e o ICMBIO, necessário pontuar que a Resolução do CONAMA n. ${ }^{\circ}$ 13/1990 impõe que as áreas caracterizadas como Unidades de Conservação, quando da instalação de atividades econômicas que possam afetar a biota, deverão ser obrigatoriamente licenciadas, visando a proteção dos ecossistemas ali existentes. 
Na maioria das vezes, os órgãos estaduais de proteção ambiental não observam essa exigência, sendo que muitas atividades econômicas são licenciadas sem a anuência prévia da chefia das Unidades de Conservação. Não fosse a exigência do CONAMA, o art. 36, parágrafo 3..$^{\circ}$, da Lei n. ${ }^{\circ}$ 9.985/ 2000 - SNUC estabelece que:

Quando o empreendimento afetar unidade de conservação específica ou sua zona de amortecimento o licenciamento a que se refere o caput deste artigo só poderá ser concedido mediante autorização do órgão responsável por sua administração, e a unidade afetada, mesmo que não pertencente ao Grupo de Proteção Integral, deverá ser uma das beneficiárias da compensação definida neste artigo.

Oportuno registrar que no caso do Rio Grande do Norte, especificamente da Flona de Açu, o órgão ambiental inicialmente responsável pela administração e como gestor de todas as unidades de conservação federais era o IBAMA, até a criação do Instituto Chico Mendes, que ocorreu através da Lei n. ${ }^{\circ}$ 11.516/2007. Daí a razão da "desintonia", pois tanto o Instituto de Desenvolvimento Sustentável e Meio Ambiente - IDEMA/RN (órgão estadual ambiental) quanto o ICMBIO são estruturas administrativas recém constituídas, ainda com competências administrativas a serem melhor definidas e consolidadas.

Inserido nesse conflito ainda existe a questão do planejamento urbano, que envolve o IDEMA/RN, ICMBIO e os órgãos municipais, num recheio de atuações descompassadas, superpostas e sobrepostas ${ }^{3}$. É imperiosa a resolução dessa questão administrativa, o que poderia ser resolvido, por exemplo, com a celebração de convênios administrativos e cursos de capacitação de servidores para atuarem em conjunto e de forma harmoniosa. Ressalte-se que o próprio ICMBIO reconhece que a Floresta Nacional de Açu está situada no sudoeste do sítio urbano da cidade de Assú, região central do Rio Grande do Norte, a $05^{\circ} 35^{\prime} 02,1^{\prime \prime}$ de latitude sul e a $36^{\circ} 56^{\prime} 41,9^{\prime \prime}$ de longitude oeste, e seu entorno está antropizado com o crescimento urbano municipal.

\footnotetext{
3 Sobre a competência comum em matéria de atuação administrativa em prol do meio ambiente foi editada a Lei Complementar n. ${ }^{\circ}$ 14/2011. Mal entrou em vigor, a Associação Nacional dos Servidores da Carreira de Especialista em Meio Ambiente (ASIBAMA) ajuizou no Supremo Tribunal Federal (STF) uma ação Direta de Inconstitucionalidade (ADI 4757). De acordo com a ASIBAMA, o meio ambiente ficou menos protegido com o estabelecimento de competências privativas para estados, DF e Municípios, uma vez que a maioria deles não está preparada para tais ações, e a União impedida de agir, pois teria perdido essas atribuições com a promulgação da lei.
}

Revista do Direito Público, Londrina, v.10, n.3, p.141-154, set./dez.2015 | DOI: 10.5433/1980-511X.2015v10n3p141 
O ideal seria que o ICMBIO se manifestasse junto ao IDEMA e ao órgão municipal orientando sobre a necessidade de manifestação prévia daquele órgão nos processos de licenciamento ambiental e urbanístico. Com isso seria iniciado um processo de interlocução com vistas a discutir e definir procedimentos para emissão de licenças ambientais e licenças urbanísticas na área de entorno da referida Unidade de Conservação, em observância às normas legais em vigência. Sendo assim, qualquer licença ambiental ou urbanística sem a anuência do ICMBIO não teria validade jurídica.

Por fim, também deve ser solucionado o impasse com relação a instituição da Flona de Açu, que a permanecer sua proteção mediante simples Portaria do MMA, somente contribuirá para maior insegurança e instabilidade jurídicoadministrativa. No entanto, não podemos deixar de fazer menção que existem doutrinadores como Fiorillo (2009, p. 152), Pedro e Franguetto (2004, p. 650) e Machado (2014, p. 976) que entendem que a criação das unidades de conservação deve ser feita mediante "ato do Poder Público", fazendo uma interpretação exegética do art. 22, da Lei n. 9.985/2000.

Ainda que sustentem este posicionamento, veja-se, por exemplo, que Machado (2014, p. 976), comenta que "nada impede, contudo, que a lei seja o instrumento utilizado para sua criação", recordando também Pedro e Franguetto (2004, p. 650) que a criação das UC's dependerá "sempre de estudos técnicos e de consulta pública que permitam identificar a localização, a dimensão e os limites mais adequados para a unidade". Isto porque existem problemas de coordenação, como já apontado, quando não há as devidas "sintonias" entre órgãos ambientais, e entre estes e o Poder Legislativo. Neste sentido, Fiorillo (2009, p. 152) traz comentário sobre uma reportagem do Jornal O Estado de São Paulo, publicado em 14 de julho de 2008, na qual o ex Ministrado do Meio Ambiente, Carlos Minc, explica a situação das Unidades de Conservação no Brasil. No texto jornalístico, é relatado que a maioria das UC's que foram criadas não foram instaladas, e que "há vários casos de sobreposição de terras de unidades de conservação federais com terras indígenas, assentamentos de reforma agrária ou áreas de preservação estaduais ou municipais" (FIORILLO, 2009, p. 153).

Em suma, atualmente pode-se afirmar que na própria órbita administrativa do governo federal há conflito entre a portaria do MMA(Flona Açu) e o Decreto do Presidente da República que institui a ZPE do Sertão. O ideal, para tentar "amenizar" a situação de descompasso legislativo na questão, seria a elaboração de uma lei local, que contemplasse o respeito às áreas da ZPE, de expansão urbana e da Flona de Açu. 


\section{CONSIDERAÇÕES FINAIS}

Estabelecer um direito ambiental sustentável é uma tarefa primordial para o Século XXI. No entanto, não se pode cogitar de um direito ambiental que venha a ferir de forma frontal a outros direitos, como o de propriedade, sem que haja uma prévia discussão sobre os espaços que sofrerão intervenção.

O caso da Flona de Açu demonstra que no Rio Grande do Norte ocorreu uma ilegalidade na criação desta Unidade de Conservação, que é alimentada pela falta de integração entre os diversos órgãos públicos envolvidos com a questão ambiental.

Urge ser necessária uma revisão dos procedimentos de criação da Flona de Açu, para que não ocorram futuros litígios envolvendo o direito de propriedade, mormente em que no seu espaço territorial foi criado uma ZPE para o desenvolvimento desta área do sertão potiguar.

Antes de querer ser legalista ao extremo, há uma razão de ser para a criação por lei destas unidades: a discussão nas casas legislativas, onde os representantes do povo (e a própria população) terão a oportunidade de observar que espaços territoriais serão protegidos, fará com que haja uma maior legitimidade democrática do processo ambiental.

Neste sentido, somos totalmente a favor de um desenvolvimento sustentável. Contudo, no caso do Rio Grande do Norte (e da Flona de Açu), deve ocorrer uma maior integração entre os órgãos ambientais de forma a ocorrer um planejamento municipal a respeitar o meio ambiental, aliado ao desenvolvimento da região, como é o caso da implantação da ZPE do Sertão, que poderá trazer grandes benefícios para esta região do nordeste do país.

\section{REFERÊNCIAS}

FIORILlO, Celso Antonio Pacheco. Curso de Direito Ambiental

Brasileiro. 10 ${ }^{\mathrm{a}}$. ed. São Paulo: Saraiva, 2009.

LIRA, Raniere Barbosa de; MARACAJÁ, Patrício Borges; MIRANDA, Marcos Antonio da Silva; SOUZA, Damião Dantas de; MELO, Stefeson Bezerra de; AMORIM, Laerte Bezerra de. Estudo da Composição Florística Arbóreo-Arbustivo na Floresta Nacional de Açu no Semi Árido do RN Brasil. Agropecuária Científica no Semi-Árido, v. 03, 2007, p. 23-30. 
LOUREIRO, Carlos Frederico Bernardo; CUNHA, Cláudia Conceição. Educação ambiental e gestão participativa de unidades de conservação: elementos para se pensar a sustentabilidade democrática. Ambiente \& Sociedade, vol. XI, n. 2, 2008, p. 237-253.

MACHADO, Paulo Affonso Leme. Direito Ambiental Brasileiro. 22a . ed. São Paulo: Malheiros, 2014.

PEDRO, Antonio Fernando Pinheiro; FRANGUETTO, Flávia Witkowski. Direito Ambiental Aplicado. In: PHILIPPI JR., Arlindo; ROMÉRO, Marcelo de Andrade; BRUNA, Gilda Collet (eds.). Curso de Gestão Ambiental. Barueri: Manole, 2004.

SANTOS, Leonardo Bis dos. Trilhas da política ambiental: conflitos, agendas e criação de unidades de conservação. Ambiente \& Sociedade, vol. XII, n. 1,2009, p. 133-150.

Artigo recebido em: 11/09/2015 Aprovado para publicação em: 12/11/2015

Como citar: LEITE, Rodrigo de Almeida. SANTOS, Marcus Tullius Leite Fernandes. Incongruências na criação de unidades de conservação: um estudo de caso da "Flona De Açu”. Revista do Direito Público. Londrina, v.10, n.3, p.141-154, set/dez.2015. DOI: 10.5433/1980-511X.2015v10n3p141. ISSN: 1980-511X. 